\title{
PERANCANGAN VISUAL ENVIRONMENT BERTEMAKAN KAMPUNG WARNA - WARNI DI INDONESIA DALAM FILM PENDEK ANIMASI "CORAZÓN"
}

\author{
Sheyrell Orvilla ${ }^{1)}$ Frans Santoso $^{2)}$ \\ School of Design-Animation, Binus University \\ sheyrellorvilla@gmail.com ${ }^{l)}$ frans.santoso@gmail.com ${ }^{2)}$
}

\begin{abstract}
Abstrak
Sebuah film memiliki aspek utama berupa cerita dan visual. Secara tidak sadar, sebanyak 95\% penonton secara sadar dan tidak sadar yang dilihat saat menonton film adalah latarnya. Walaupun desain karakter dan animasi karakter tidak terlalu menonjol, namun apabila latarnya memiliki kesesuaian yang pas dan mendukung, mood dan emosi dalam sebuah cerita dapat tercipta dengan baik. Sebuah latar visual yang bagus ialah sebuah visual dimana visual tersebut dapat membuat para penonton ingin dan ingin untuk melihat lagi dan lagi. Sebuah visual tentu tidak akan terlihat menarik tanpa environment yang mendukung. Environment yang mendukung tentu didukung oleh aspek - aspek. Salah satu aspeknya ialah warna. Memiliki warna dalam sebuah environment bisa sangat membantu. Kampung Warna - Warni Jodipan, Kampung 3D di Malang, dan Kampung Pelangi merupakan sebuah kampung yang dapat dijadikan referensi untuk sebuah kompleks yang bewarna. Mulai dai warna - warna yang ada di setiap rumah, hiasan - hiasan bewarna yang kreatif bentuknya, grafiti buatan warga, dan juga tentunya bentuk medan tanah yang menarik.
\end{abstract}

Kata Kunci : Warna, Environment, Visual, Kampung Warna - Warni

\begin{abstract}
A film has a major aspect, there are story and visual. Unconsciously, as many as 95\% of audience sees while watching a movie is the setting and visuals. Although even if the design of the character and the animation of the character are not very prominent. If the background has a promising fitting fit and support the mood and the emotion, the story can be created properly and touched the audience. A good visual background is the visuals that can make the audience want and want to see more, again, and again. A visual would not look attractive without a supportive environment. A supportive environment is the one that supported by aspects. Color is one of the aspects. Having color in a environment can be very helpful. Kampung Warna - Warni Jodipan and Kampung 3D in Malang both and Kampung Pelangi in Semarang are places that can be used as a references. Starting from the colorful color each house has, the attractive shape, gravity made by residents, and also the form of its land that so unique.
\end{abstract}

Keyword : Color, Environment, Visuals, Land, Places. 


\section{PENDAHULUAN}

Bersama cerita, visual merupakan sebuah aspek utama dalam sebuah film. Penggunaan visualisasi dan animasi 3D dalam bidang perfilman, telah digunakan sejak lama oleh para produsen film untuk mendapatkan hasil film yang lebih menarik. White (2006) menjelaskan bahwa disaat penonton menonton film, secara sadar atau tidak $95 \%$ yang dilihat adalah latar. Walaupun desain karakter dan animasi tidak terlalu bagus, namun apabila latar sesuai dan mendukung, mood dan emosi dalam cerita tetap dapat tercipta dengan baik. Seperti yang dikatakan oleh Doug Rogers (production designer film animasi Tangled) dalam video A Tangled World: Creating The Look berkata, dia ingin menciptakan sebuah dunia yang menawan sehingga membuat penonton ingin melihat lagi dan lagi.

Untuk mendapatkan sebuah environment yang mendukung, perlu diperhatikan beberapa aspek aspek seperti style, color pallete, tekstur, karakteristiknya, dan pencahayaan dari sebuah environment. Hal ini diuraikan dalam buku The Art of Madagascar 2 Escape Africa (Beck, 2008). Environment adalah aspek yang membentuk dunia dimana karakter akan tampil dalam sebuah animasi dimana karakter rtersebut hidup, bergerak dan berinteraksi dengan elemen - elemen animasi yang lain. Margaretha, dalam laporannya tugas akhirnya menuliskan bahwa environment merupakan salam satu elemen paling penting dalam animasi karena mendukung suasana cerita. environment ini mendukung penjelasan seuasana yang dirasakan oleh karakter dalam suatu animasi, sehingga penonton dapat ikut merasakan berada didalam cerita.

Kampung Warna Warni Jodipan, Malang merupakan sebuah kampung sekaligus tempat wisata di Malang, kampung ini memiliki daya tarik berupa warna - warna yang ada di setiap rumah seperti kota yang ada di Rio De Janeiro, dimana tempat tersebut penuh dengan warna - warni yang indah dan menarik untuk dilihat dan dikunjungi. Terinspirasi dari kota yang terdapat di kota Rio De Janeiro, Brazil tempat ini juga memiliki keunikannya sendiri. Dikarenakan environment menjadi salah satu elemen penting dalam mendukung tersampaikannya sebuah cerita animasi, penulis berkeinginan untuk membahas desain environment Kampung Warna - Warni Jodipan yang berada di kota Malang. Dengan tujuan agar environment yang ada didalam film pendek yang akan dibuat dapat terbentuk dengan baik.

\section{Kajian Literatur}

Penulis melakukan tinjauan pustaka serta survey untuk meneliti bentuk environment, bentuk landscape, dan bentuk properti pendukung sebuah environment dalam sebuah cerita pendek animasi.

\section{Teori Animasi}

Animasi berasal dari kata dalam bahasa inggris yaitu animate yang artinya menghidupkan, memberi jiwa, dan menggerakkan benda mati. Animasi juga berasal dari kata latin anima, yang secara harafiah berarti jiwa (soul), atau animare yang berarti kehidupan (vital breath). Menurut Vaughan (2004), animasi adalah usaha untuk membuat presentasi statis menjadi hidup. Merupakan sebuah perubahan visual sepanjang waktu yang memberikan kekuatan besar pada proyek multimedia dan halaman web yang dibuat.

Setelah ditemukannya teknologi digital yang lebih maju pada tahun 1980an, setelah berdirinya Pixar pada tahun 1986 sebagai studio animasi komputer pertama. Namun dampaknya baru terasa sepuluh tahun kemudian 
(tahun 1990-an) terutama saat visual effect pada film dan dengan di tandai adanya film animasi panjang 3D (Tiga Dimensi) pertama didunia yang berjudul "Toy Story" pada tahun 1995 oleh studio animasi Pixar. Setelah hal tersebut makin berkembanglah film animasi di dunia. Memiliki perubahan yang sangat luar biasa, animasi mutakir di era digital animasi global yang hibrid dengan film live shot. Film - film tersebut adalah bentuk kompleksitas animasi yang sudah jauh melampau era - era sebelumnya, baik dari sis bentuk/rupa, gerak animasi, teknologi, media, cerita, dan sebagainya.

Animasi merupakan proses membuat objek yang asalnya merupakan sebuah benda mati, kemudian secara berurutan disusun dalam posisi yang berbeda sehingga seolah - olah menjadi hidup. Paul Roget, Joseph Plateau dan Pierre Desvigenes berhasil membuktikan bahwa mata manusia cenderung menangkap urutan gambar - gambar pada tenggang waktu tertentu sebagai sebuah pola. Hal ini mereka buktikan melalui peralatan optik yang mereka buat. Secara umum animasi dapat didefisinikan sebagai suatu sequence gambar yang ditampilkan pada tenggang waktu (timeline) tertentu sehingga tercipta sebuah ilusi gambar bergerak. Atau dapat disebut juga bahwa animasi adalah menggerakkan objek agar tampak lebih dinamis. Untuk membuat ilusi gerakan, gambar yang ditampilkan akan diganti secara terus menerus dengan gambar baru yang mirip dengan gambar sebelumnya. Penggantian yang terus menerus ini mempunyai kecepatan 24 atau 30 frame per detik. Satu menit animasi membutuhkan 720 hingga 1800 gambar, bergantung pada kualitas animasinya tersebut. Semakin banyak frame yang digunakan semakin halus animasi yang dihasilkan.

Thomas dan Johnston memberikan 12 prinsip animasi yang diadopsi dari produksi Disney. Prinsip - prinsip animasi ini sangat pas digunakan untuk animasi kartun, tetapi dapat digunakan untuk animasi yang serius. Ke-12 prinsip tersebut adalah, Anticipation, Squash and Stretch, Staging, Straight-ahead Action and Pose to Pose, Follow-through and Overlapping Action, Ease In and Ease Out, Arc, Secondary, Action, Timing, Exaggeration, Solid Drawing, Appeal

Model animasi 2D dibuat dan/atau diedit di komputer menggunakan gambar bitmap 2D atau vektor 2D. animasi ini termasuk teknik animasi tradisional yang teroromatisasi pada komputer. Misalnya tweening, morphing, onion skinning dan interpolated rotoscoping. Tweening atau inbetweening merupakan proses pembuatan framesecara otomatis antara dua gambar yang berbeda untuk memberikan tampilan bahwa gambar pertama akan berubah menjadi gambar kedua. Perubahan ini dapat berupa perubahan bentuk atau perubahan koordinat. Penggunaan ini sangat berguna bagi animator terutama dalam kecepatan membuat animasi. Sedangkan Morphing merupakan sebuah efek kusus animasi yang berguna untuk mengubah (morph) satu gambar menjadi gambar lain dengam perubahan yang halus.

Animasi 3 Dimensi (3D) adalah suatu objek animasi yang terdapat dalam ruang 3D. Objek ini bisa berputar dan berpidah seperti objek aslinya dan merupakan penciptaan gambar bergerak dalam ruang digital tiga dimensi. Dilakukan dengan membuat frame yang mensimulasikan masing-masing gambar, difilmkan dengan kamera firtual. Dan output-nya berupa video yang sudah di render atau realtime untuk membuat game. Animasi 3D biasanya memiliki 24 - 60 frame di tiap detiknya. Semakin banyak frame yang dimiliki semakin smooth gerakan yang dihasilkan.

Konsep animasi 3D sendiri adalam sebuah model yang memiliki bentuk, 
volume, dan ruang. Objek 3D memiliki koordinat X,Y, dan Z. Animasi 2D hanya memiliki dua koordinat yaitu $\mathrm{X}$ dan $\mathrm{Y}$ sehingga animasi $2 \mathrm{D}$ hanya dapat digerakkan ke dua arah, yaitu kekanan kiri (X) dan atas - bawah (Y). pada animasi 3D, objek dapat digerakkan ke tiga arah, yaitu kanan - kiri (X), atas bawah (Y), dan depan - belakang (Z). Dalam pembuatan film dalam bentuk grafis 3D menggunakan komputer, biasanya dibagi menjadi tiga tahap, yaitu; Modeling, Animation, dan Rendering.

\section{Mise En Scene}

Mise En Scene digunakan dalam pembelajaran mengenai film, terutama visual stylenya. Kata Mise En Scene sendiri berasal dari Perancis, walaupun sudah dibahasa inggriskan pada tahun 1833 silam. Memiliki arti 'to put on stage' yang bagi mereka yang mempelajari tentang film Mise En Scene memiliki arti yang bisa juga disebut sebagai "The contents of the frame and the way that they are organized". Mise En Scene merupakan kumpulan dari Lighting, Costume, Decor, Properties, dan tentu juga para pemainnya. Hal tersebut juga tidak luput bahwa Mise En Scene juga mencangkup kostum, makeup, hair makeup, ekspressi muka, dan lain sebagainya. Penyusunan konten yang ada tidak hanya mempengaruhi hubungan sang aktor kepada dekorasi sekitarnya tetapi juga sang aktor dengan kamera dan view yang dilihat oleh penonton. Sehingga apabila membicarakan soal Mise En Scene pasti juga akan membicarakan tentang framing, pergerakan kamera, penggunaan lensa, dan pemilihan fotografi lainnya. Mise En Scene memiliki pengaruh besar terhadap apa yang penonton lihat, bagaimana penonton 'diajak' untuk ikut melihat.

Mise En Scene ini sendiri memiliki 5 element. Ke-5 elemen tersebut ialah; Setting and props, Costume, hair and pake up., Facial expression and body language, Lighting and color, Arrange of element in frame.

\section{Cinematography}

Teori dasar tentang pembuatan film meliputi konsep dalam sinematografi. Sinematografi merupakan sebuah kata serapan dari bahasa inggris cinematography yang berasal dari bahasa Latis kinema yang berarti 'gambar'. sebabagi ilmu terapan, sinematografi merupakan bidang ilmu yang membahas tentang teknik menangkap gambar yang dapatkan menyampaikan ide atau dapat mengemban cerita (Frost, 2009: 8). Sinematografi memiliki objek yang sama dengan fotografi, yakni menangkap pantulan cahaya yang mengenai benda (Carroll, 1996). Perbedaan dari sinematografi dan fotografi ialah apabila fotografi menangkap gambar tunggal, sinematografi menangkap rangkaian gambar sehingga sinematografi adalah gambungan antara fotografi dengan teknik perangkain gambar atau dalam sinematografi disebut montase (montage).

Ptatista (2008: 89) mengungkapkan dalam sebuah ilmu sinematigrafi, seorang pembuat film tidak hanya merekam setiap adegan, melainkan bagaimana mengontrol dan mengatur setiap adegan yang diambil, seperti jarak, ketinggian, sudut, lama pengambilan, dan lainnya. Hal ini menjelaskan bahwa sinematografi secara umum memiliki tiga unsur yakni, Kamera atau Film, Framing, dan Durasi.

Framing dapat diartikan sebagai pembatasan gambar oleh karema,seperti batasan wilayah gambar atau frame, jarak ketinggian, pergerakan kamera, dan sebagainya (2008: 100). dalam sebuah film, hampir tidak pernah seluruh unsur objek dioerlihatkan kepada penontonnya. Pembatasan inilah yang disebut juga sebagai framing, 
Durasi. Setiap shot memiliki durasi yang beragam sesuai dengan tuntutan naratif. Satu shot dapat berdurasi kurang dari satu detik, bisa pula sampai dengan beberapa menit bahkan jam. Secara teknis, sebuah shot yang melebihi dari durasi rata - rata (9 - 10 detik) disebuh long take

\section{Lighting}

Dalam sinematografi, cahaya memiliki fungsi untuk menyinari objek, menghilangkan bayangan yang mengganggu, membuat efek khusus, dan menghasilkan gambar yang artistik. Tata letak cahaya dalam karya foto menjadi syarat utama untuk membuat suato foto yang baik. Pada dasarnya teori pencahayaan dan sudut datang serja teori pantulan sering dialami setiap hari, terutama pada hari cerah. Lighting memiliki tiga point khusus dalam dunia sinematografi yang perlu diperhatikan, yaitu; Key Light, Fill Light, dan Hair Light.

\section{METODE PENELITIAN}

Selama proses penelitian, penulis menerapkan metode perancangan metode penelitian sebagai berikut.

\section{Metodologi Desain}

Dalam proses mendesain, terdapat 7 tahap yakni define, research, ideate, prototype, select, implement dan learn. Empat pertama dari tujuh tahap yang telah disebut merupakan tahap - tahap yang dilakukan pada proses prepoduksi.

\section{Define}

Merupakan tahapan pertama dalam proses mendesain. Tahap ini selalu melibatkan membuat atau menerima. Ide awal harus memiliki tujuan yang dipenuhi oleh desain dan memungkinkan juga untuk ditulis. Ide awal merupakan sebuah bentuk yang sederhana.

\section{Research}

Pada tahap ini merupakan tahap dimana pengumpulan data informasi di terapkan. Ketika sebuah ide telah disetujui dan ditetapkan, desainer memulai tahap research untuk mencari segala iformasi yang dibutuhkan dalam penbentukan desain. Hasil dari research ini dapat berupa data kualitatif maupun kuantitatif, tidak menutup kemungkinan juga mencangkup keduanya.

\section{Ideate}

Ideate merupakan sebuah tahap dimana desainer menciptakan sebuah solusi yang berpotensi. Hasil ideate ini berpacu pada hasil research yang telah dilakukan sebelumnya. Pada tahap ini meliputi brainstorming, sketsa ide. Tim desain juga harus memilih metode mana yang akan digunakan tergantung dari berapa besar dana yang ada dan desain seperti apa yang harus dibuat.

\section{Prototype}

Setelah dihasilkan beberapa variasi solusi yang potensial, prototype memungkinkan untuk menguji dan menyediakan dasar yang lebih baik sebagai pembanding pada tahap seleksi apakah ide tersebut bekerja dengan baik sebagai objek fisik atau tidak.

\section{Select}

Select atau pemilihan merupakans tahap dimana satu dari semua solusi desain yang ada dipilih. Biasanya desain yang terpilih merupakan desain yang paling mendekati dengan brief yang telah diberikan.

\section{Implement}

Pada tahap ini, desainer memberikan hasil desain yang telah mereka kerjakan dengan spesifikasi format yang telah ditentukan. Tim desain biasanya bersama manajemen proyek bekerja sama agar hasil akhir sama dengan ekspektasi 
dan juga menjaga agar proyek tetap pada anggaran dan tepat waktu

\section{Learn}

Dalam hal ini merupakan proses pembelajaran dari apa yang sudah dikerjakan. Merupakan tahapan fed back dimana hasil desain yang telah selesai apakah sudah berhasil atau ada yang perlu diperbaiki. Fed back ini dapat menjadi pembelajaran untuk proyek selanjutnya.

\section{Data Primer}

Pengumpulan data primer dilakukan dengan cara survei tempat, yaitu survey ke tempat-tempat perkampungan yang mendukung tema. Kampung - kampung yang di survey ialah Kampung Pelangi di Semarang, Kampung Warna - Warni Jodipan di Malang, dan Kampung 3D di Malang. Data ini ddapatkan dari terjun langsung mendatangi tempat - tempat tersebut serta mengambik foto - foto yang sekiranya dapat digunakan.

\section{Data Sekunder}

Data sekunder didapatkan dari pengumpulan literatur dari internet, dan metode wawancara.

\section{Metode Analisa Data}

Analisa data yang dilakukan dalam perancangan ini adalah menganalisa data survey dan wawancara, serta data literatur dan dari internert.

\section{HASIL DAN PEMBAHASAN}

\section{Penulisan Judul "CORAZÓN"}

Untuk desain judul, penulis memiliki beberapa alternatif yang bisa digunakan. Dari ke empat font tersebut nantinya akan dipilih satu yang paling sesuai dengan film pendek animasi tersebut.

\section{COPAZón Corazón}

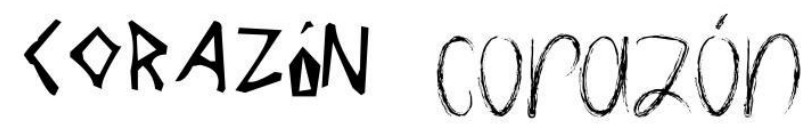

Font yang menjadi Alternatif Judul

FERA L

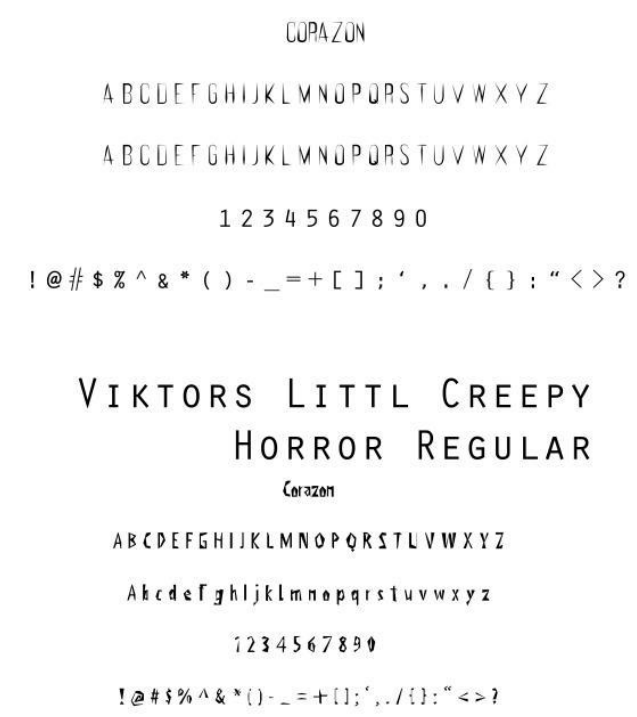

WOLVES AND RAVENS

REGULAR

$\angle Q R A Z Q N$

$A B<D \& F \& H I J K L M N \otimes P Q R 4 T U V W \times Y Z$

$A B<D \& F G H I J K L M N \otimes P Q R 4 T U V W \times Y Z$

1274567880

SPOOKY HALLOWEEN

corozon

ABCDEFCHIJKLUNDPQRSTUUWXY2

Ancoefgnijkimnooarstuviexyz

1234567890

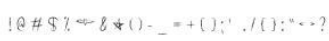

\section{Studi Bentuk dan Landscape \\ Environment}

Dari hasil yang telah didapat, berikut merupakan beberapa visual yang akan digunakan. 


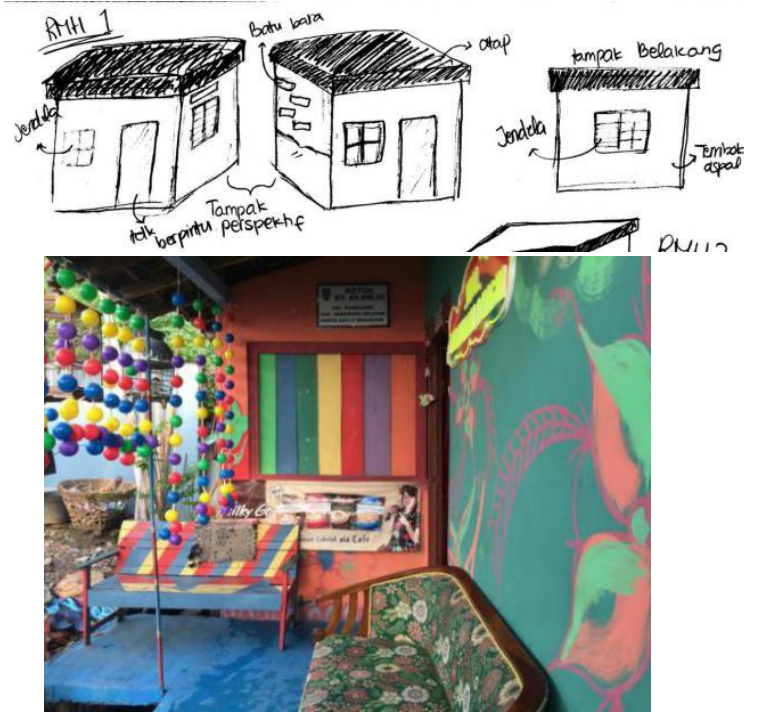

Gambar 2.1. Rumah 1

Salah satu bentuk rumah yang akan penulis buat ialah seperti gambar 2.1. bentuk rumah ini memiliki bentuk yang simple seperti kotak/kubus/persegi panjang. Memiliki material tembok beton dan batu bata di bagian sampingnya. Memiliki jendela yang tebuat dari kayu.
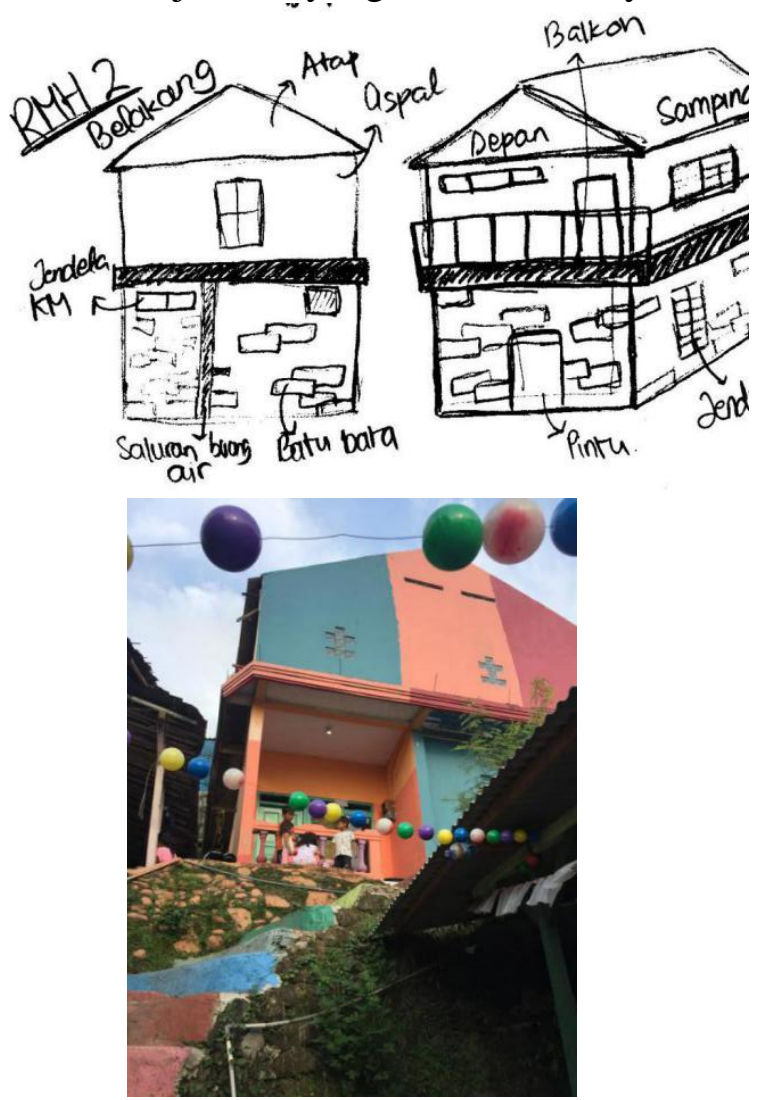

Gambar 2.2. Rumah 2
Bentuk rumah kedua ialah seperti gambar 2.2. Pada rumah model ini bentuknya memiliki 2 tingkat. Tergabung terbuat dari tembok dan batu bata. Memiliki atap berbentuk segitiga dan balkon.
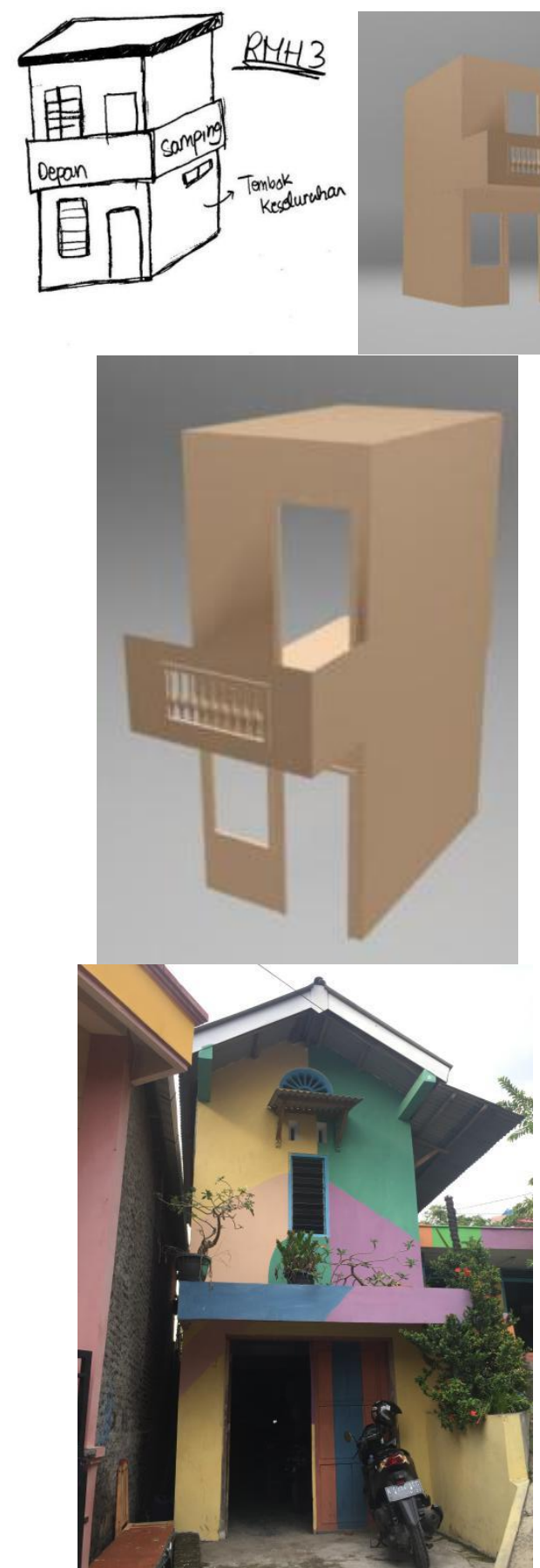

Gambar 2.3. Rumah 3

Rumah ketiga juga memiliki 2 tingkat, hanya saja rumah bentuk ini ukurannya lebih kecil daripada bentuk 
rumah 2. terbuat dari keseluruhan tembok, dan kaca serta kayu dibagian untuk pintunya.
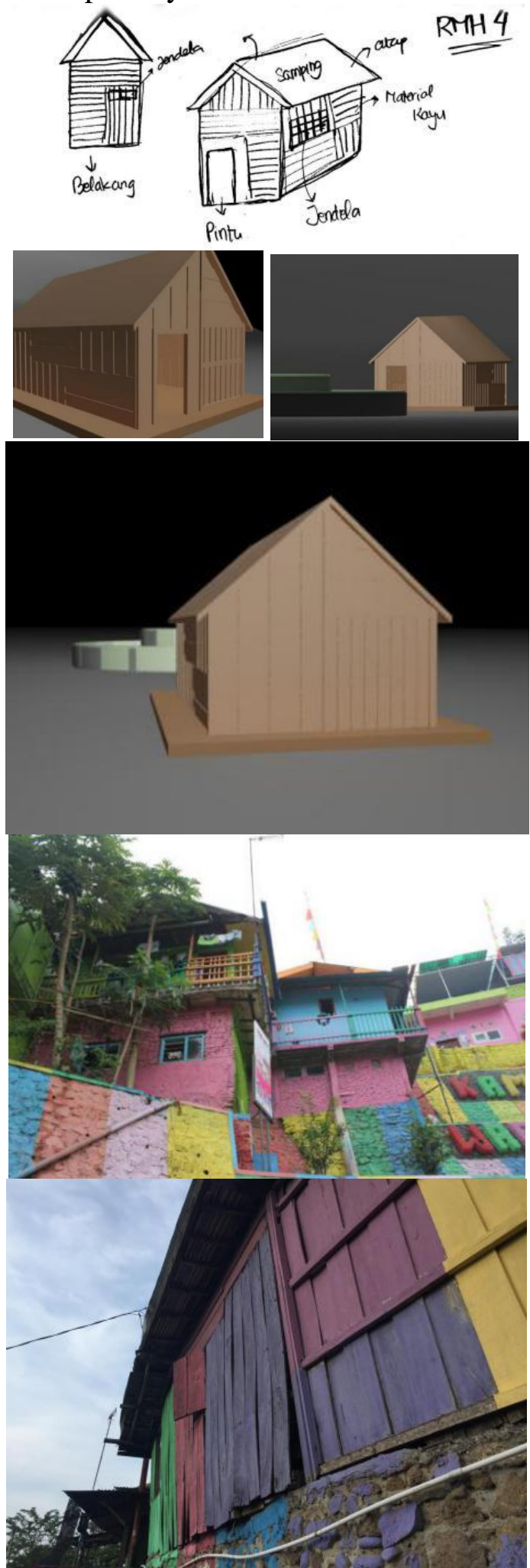

Gambar 2.4 Rumah 4
Rumah ke 4 merupakan rumah yang berbeda dari yang lainnya. Rumah ini berbentuk hapir sama, yang membedakan ialah material yang digunakan. Rumah 4 ini menggunakan kayu untuk keseluruhan bentuk rumahnya. Berbentuk persegi panjang dan memiliki atap segitiga. Terdiri dari satu lantai.
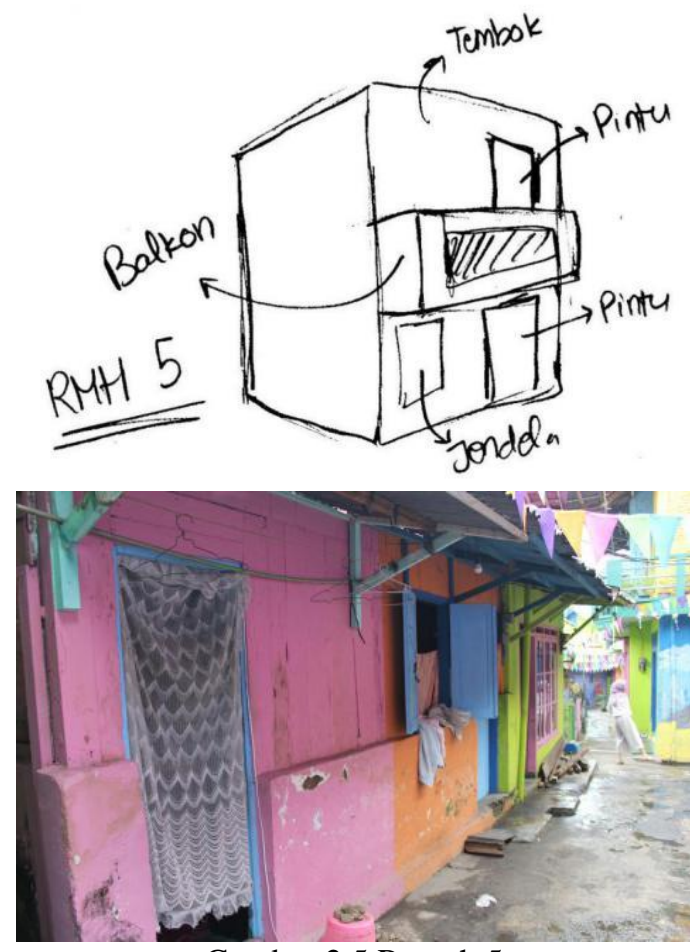

Gambar 2.5 Rumah 5

Tipe rumah ini memiliki kemiripan seperti rumah 4. apa yang membedakan ialah rumah tipe ini menggunakan batu bata sebagai bahan utama pembentukan rumahnya. Memiliki 2 tingkat dan balkon.

Selain tipe bentuk rumah, ada pula lokasi secara keseluruhan yang dapat diambil dari tempat yang telah di survey.

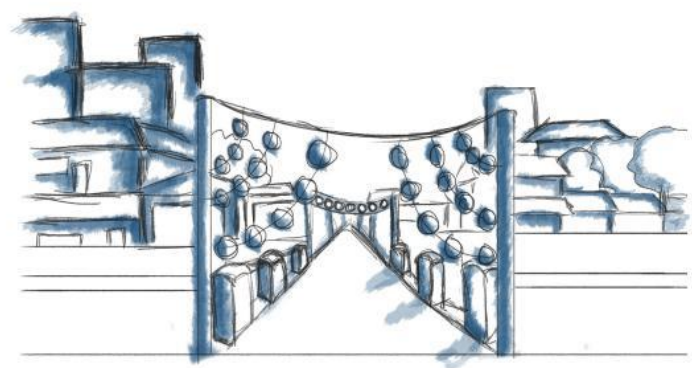




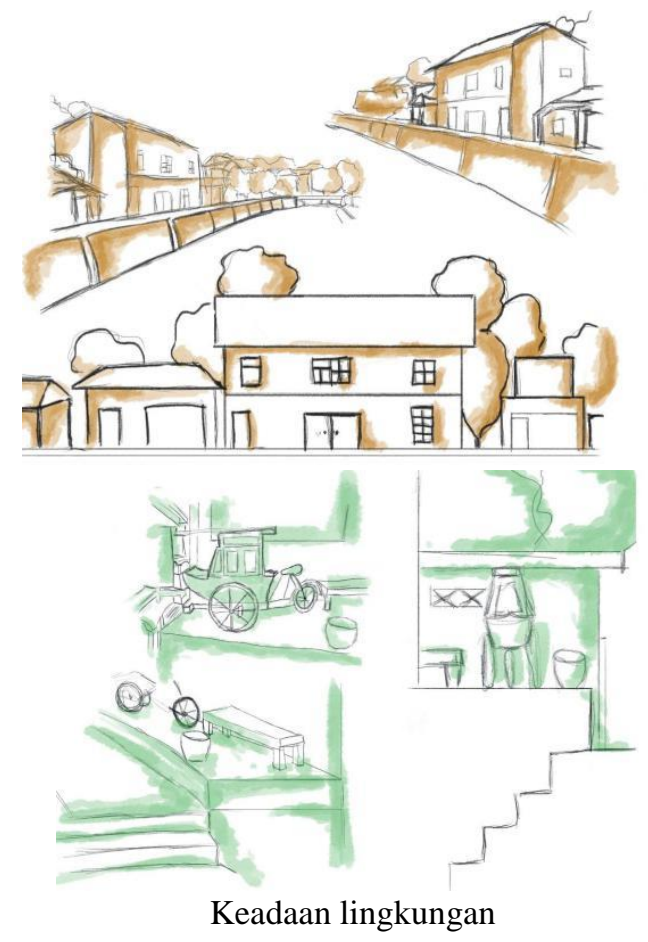

\section{Studi Properti Pendukung}

Tidak hanya warna-warni dari hasil pengecat an, keunikan warna-warna yang tedapat di Kampung Pelangi ini ialah banyaknya hiasan-hiasan bewarna-warni yang merupakan ide hasil kerja warga yang mendaur ulang barang-barang plastik bekas yang dijadikan hiasan gantungan, tempat sampah, tugu selamat datang, dsb.

Dari survey yang telah penulis lakukan, berikut merupakan bentuk dan props yang nantinya akan penulis gunakan dalam membuat properti pendukung short animasi.
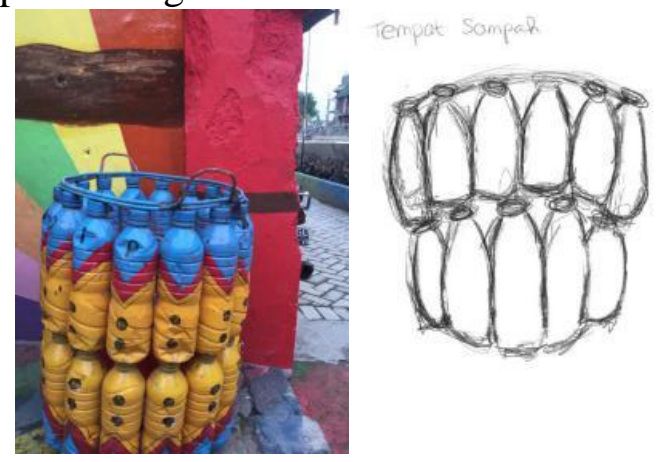

Gambar 2.6 Tempat Sampah

Foto tersebut memperlihatkan sebuah tempat sampai yang cukup unik, bentuk ini merupakan bentuk tempat sampah yang dominan ada di Kampung Pelangi Semarang. Karena bentuk tempat sampah ini dominan ada di setiap sudut yang penulis temukan, maka penulis menentukan untuk membuat tempat sampai ini juga ada di setiap sudutnya nanti.

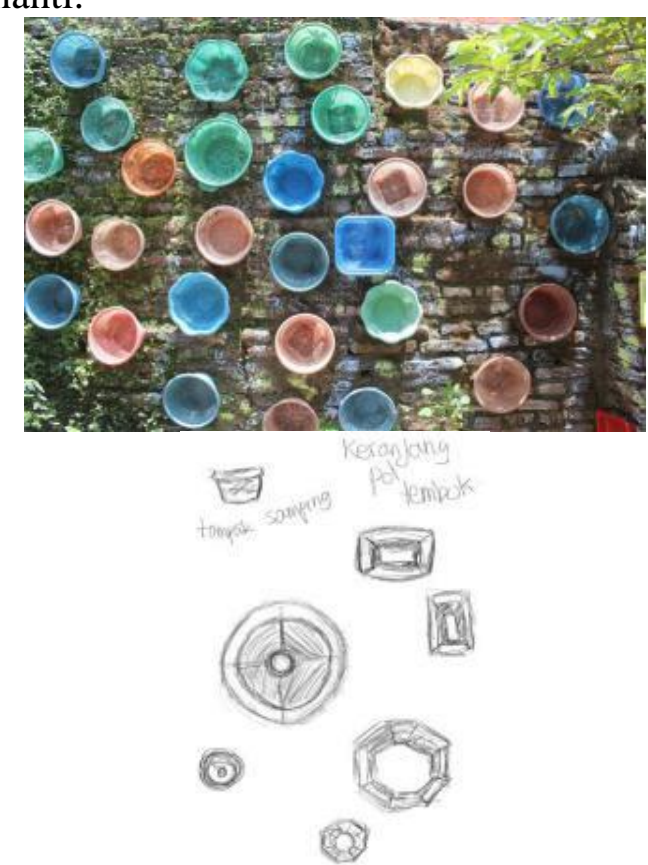

Gambar 2.7 Hiasan pada Tembok

Bentuk ini merupakan bentuk hiasan yang cukup banyak ada di lokasi survey yang penulis lakukan, maka dari itu penulis ingin menggunakan motif dan bentuk yang ada untuk penulis gunakan nanti.

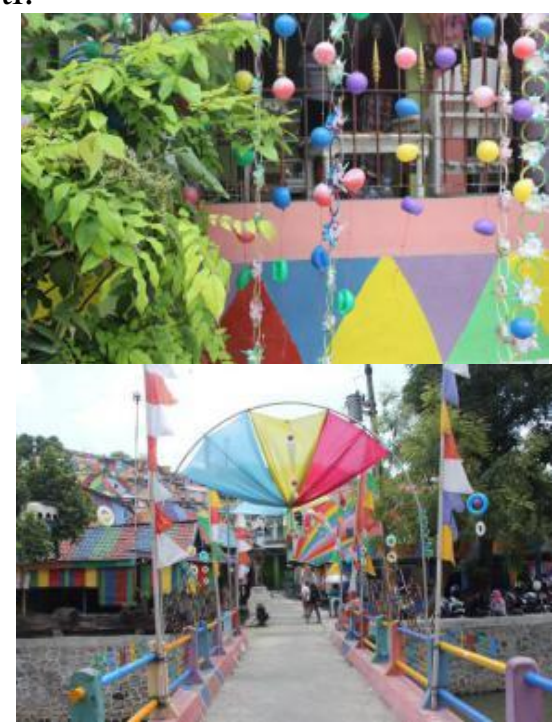




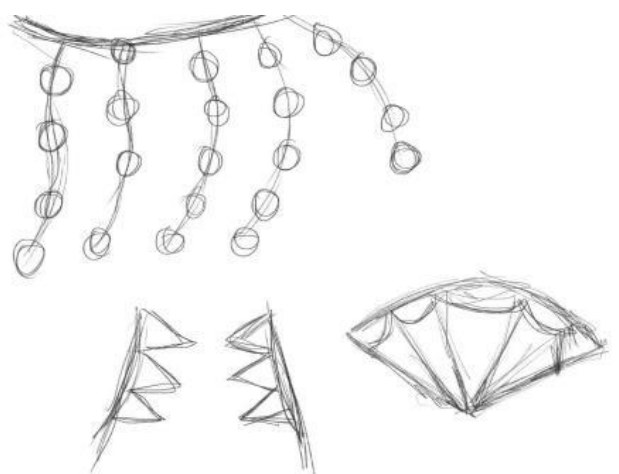

Gambar 2.7 Hiasn Gantungan Bola, Bendera Pinggir Kali, dan Hiasan Kipas

Hiasan bola-bola yang dirajut disatukan oleh sebuah tali dan digantung merupakan sebuah hiasan yang banyak dimiliki oleh Kampung Pelangi tersebut. Bola - bola yang digunakan merupakan sebuah bola plastik yang suka digunakan utuk main lempar bola saat 17 an berlangsung, selain itu warna - warni yang dimiliki bola tersebut juga menambah keindahan warna yang ditimbulkan.

Selain dari bola-bola hiasan tersebut ada pula bendera bendera yang berbentuk segitiga yang dipasangkan di sebuah tiang. Bendera-bendera tersebut memiliki warna-warna yang berbeda di setiap bentuknya sehingga membuat menjadi lebih bewarna.

Bentuk yang seperti kipas merupakan sebuah bentuk yang penulis dapatkan pada saat berjalan di dalam gang-gang. Selain didalam gang, penulis juga menemukan bentuk tersebut berada di tembok-tembok rumah penduduk, sehingga merupakab sebuah benda yang banyak digunakan di Kampung tersebut.
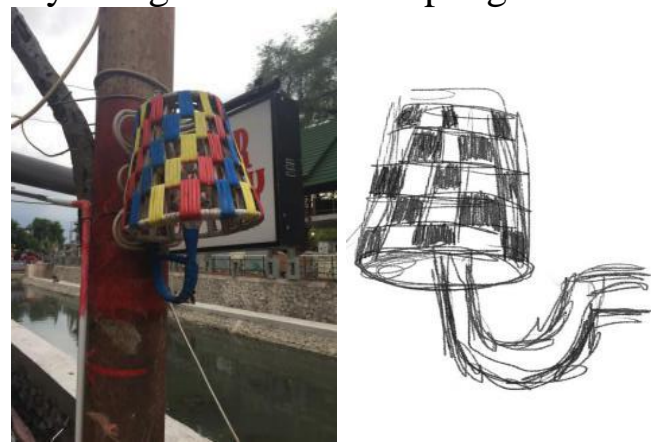

Gambar 2.8 Lampu Jalan
Lampu tersebut pada malam hari akan menyala dan menerangi sebagian jalan yang ada. Dikarenakan set penulis nantinya kebanyakan akan ada pada malam hari, maka lampu jalan merupakan salah satu props yang akan banyak penulis gunakan.

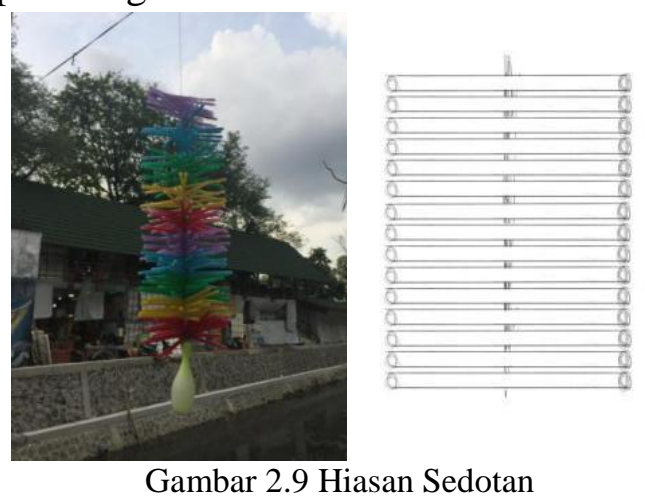

Hiasan sedotan tersebut merupakan hiasan yang banyak dimiliki. Mau di pinggir kali ataupun tergantung di sela sela gang yang ada. Selain bentuk itu ada juga bentuk lainnya.
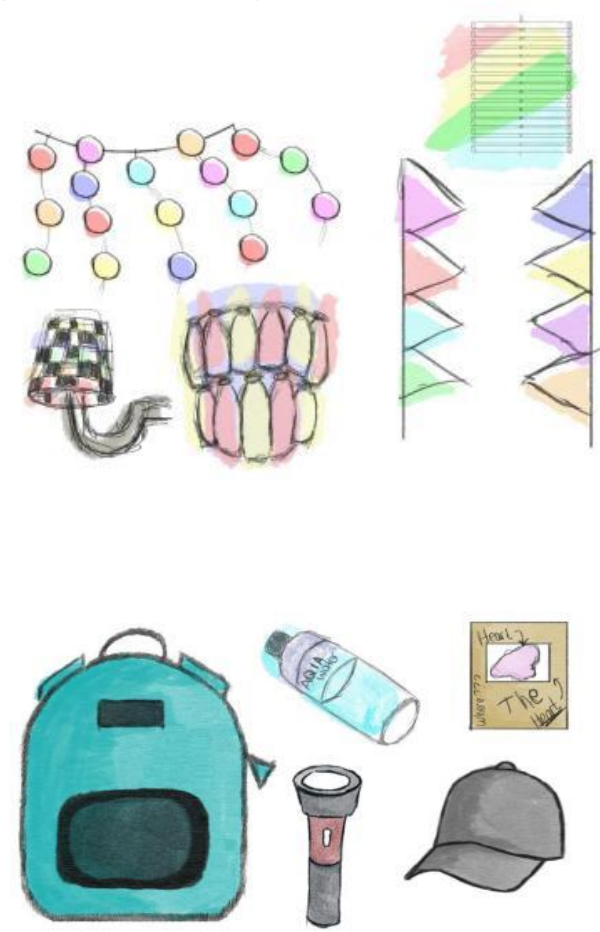

Porperti yang digunakan

\section{Pembentukan Character}

Terdapat tiga karakter utama dalam film animasi pendek "CORAZÓN". 
Pertama sang anak laki - laki yang bernama Hart. Hart diambil dari bahasa Belanda yang berarti Heart dalam bahasa inggris dan berarti Hati dalam bahasa Indonesia. Karakter kedua adalah seorang anak permpuan bernama Hona, ia periang dan suka bermain. Ia sangat senang saat pertama kali bertemu Hart. Karakter terakhir adalah karakter sang ayah.
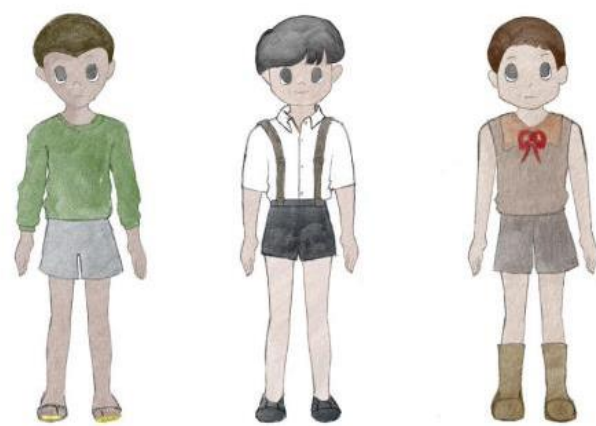

Karakter alternatif 'Hart'
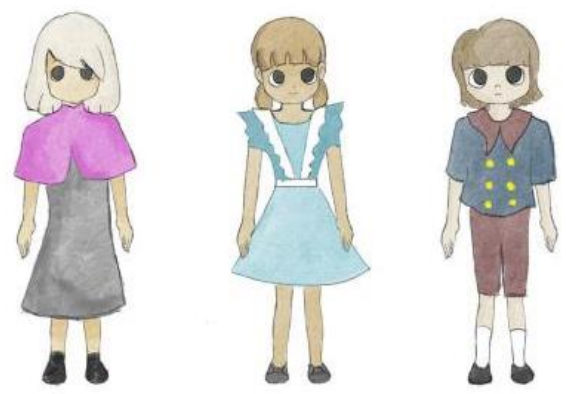

Karakter alternatif 'Hona'
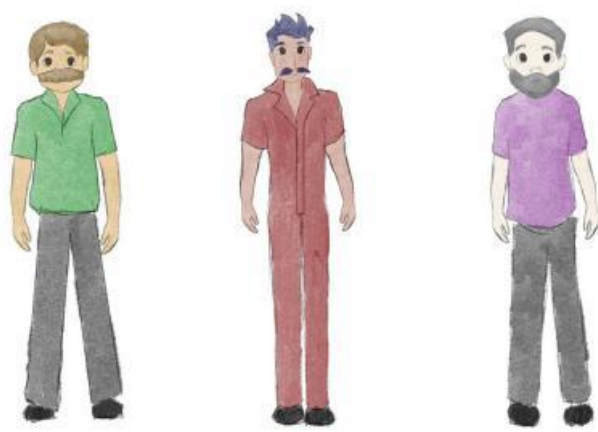

Karakter alternatif 'Ayah'

\section{DAFTAR PUSTAKA}

\section{Sumber Buku}

Bordwell, D. and Thompson, K. (1979). FILM ART: AN INTRODUCTION edisi keempat. McGraw-Hill, Inc.
Binanto, I. (2010). Multimedia Digital Dasar Teori dan Pengembangannya. Yogyakarta: Penerbit Andi.

Gibbs, J. (2012) Mise-En-Scene Film Style and Interpretation. Columbia University Press Publisher.

Zeembry. (2006) 12 Jurus Pamungkas Animasi Kartun dengan Flash 8. Jakarta: PT Alex Komputindo,

Vinsensius Sitepu. (2005) Membuat Animasi Alam dengan Corel Bryce. Jakarta: PT Alex Komputindo.

Yudistira. B.A.. (2007). Buku Latihan 3D Studio MAX 9.0. Penerbit: PT Alex Komputindo, Jakarta. Hal. 143

\section{Sumber Internet}

http://yahdiinformatika.staff.telkomuniv ersity.ac.id/penerapanvisualisasi-dan-animasi-3ddalam-dunia-perfilman/

https://animation.binus.ac.id/2017/02/08/ sejarah-animasi-indonesiasebuah-pengantar/

https://www.slideshare.net/houseofamos/ 5-elements-of-mise-en-scene

http://www.satriamultimedia.com/artikel _mengenal_teori_animasi.html

http://www.wandah.org/dkv/sinematogra fi

http://sir.stikom.edu/22/5/BAB\%20II.pdf http://sir.stikom.edu/345/6/BAB\%20III.p df 
JURNAL DESAIN | Volume 05, Nomor 02 | Januari 2018: 123-134

http://greathemelkor.blogspot.co.id/2009

/04/sinematografi.html

http://digilib.its.ac.id/public/ITS-paper29609-3407100109-Paper.pdf

https://montasefilm.com/long-take/ 